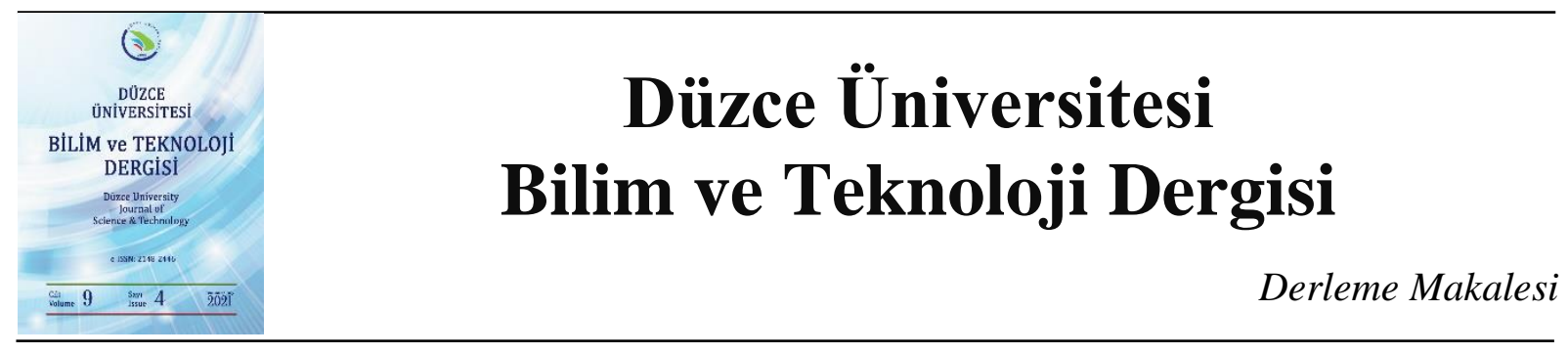

\title{
Otonom Araçların Teknolojik Gelişim Süreci ve Trafik Seyir Özelliklerinin İncelenmesi
}

\author{
Mustafa KARAŞAHIN ${ }^{a}$, (D) Mehmet Çağrı KIZILTAŞ ${ }^{\text {b, * }}$ \\ ${ }^{a}$ İş̧aat Mühendisliği Bölümü, Mühendislik Fakültesi, İstanbul Gelişim Üniversitesi, İstanbul, TÜRKIYYE \\ ${ }^{b}$ İnşaat Mühendisliği Bölümü, Mühendislik Fakültesi, İstanbul Gelişim Üniversitesi, İstanbul, TÜRKIYE \\ * Sorumlu yazarın e-posta adresi: cagriuck@hotmail.com
}

DOI: 10.29130/dubited.908525

\begin{abstract}
$\underline{\mathrm{OZZ}}$
Otonom araçlar gelecek ulaştırması ve kentinin en önemli unsurlarından bir tanesini teşkil etmektedir. İçinde bulunduğumuz yüzyılda kentleşme, sürdürülebilirlik ve dijitalleşme en temel unsurlar olacaktır. Bunun merkezinde ise otonom araçlar etkin ve belirleyici bir konuma sahiptir. Otonom araçların trafikte ağırlığı arttıkça ulaştırma ve kentleşme de yeniden şekillenecektir. Bu çalışma kapsamında, öncelikle otonom araç özelliklerinin kent ve ulaşımla ilişkisi ortaya konulmuştur. Ardından ise otonom araçların gelişim süreci detaylı olarak ele alınmıştır. Akabinde otonom araçlarda güvenlik ve emniyet konusu değerlendirilmiş bu olup sonrasında otonom araç teknolojileri çok yönlü olarak paylaşılmıştır. Son olarak da bu kapsamda sonuçlar verilmiştir.
\end{abstract}

Anahtar Kelimeler: Otonom araç, trafikte seyir, ulaştırma sistemi

\section{Review of Autonomous Vehicle's Improvement Period and On This Context Traffic Navigation Features}

\begin{abstract}
Autonomous vehicle is one of the most important element of future transport. Urbanization, sustainability and digitalization are going to be the most basic parameters in this century. At the central point of this, autonomous vehicle has an effective and determinant position. As traffic penetration of autonomous vehicle increases, transportation and urbanization are going to reshape. In this paper, firstly interaction between urbanization and transportation with autonomous vehicles is discussed. Then improvement period of autonomous vehicles is evaluated in detail. After these, safety and security issues of autonomous vehicles are discussed. Later on autonomous vehicle technologies are shared with multi directionally. Lastly conclusions are given.
\end{abstract}

Keywords: Autonomous vehicles, traffic navigation, transportation system 


\section{GİRIS}

Kent kaynaklarının üretime dönüşümü sırasında, kentteki hareketlilik koşulları da değişmektedir. Bilgi ve iletişim teknolojisindeki hızla artan gelişmeler ulaştırma sistemlerine de nüfuz etmektedir. Çalışmalar, talep odaklı hareketlilik yönetimi yaklaşımının gelişimi için, gelecekte çok modlu ve esnek bir ulaştırma sistemi ile ulaştırma arzının sağlanmasına yönelmiştir. Kentsel hareketliliğin omurgası olarak, toplu ulaştırmanın rolü ise daha da artmakta ve sürekli modernize olmaktadır. Örneğin bütünleşik bir planlamada, yeşil dostu hareketliliğin bir parçası olarak bisikletli ve yaya ulaşım modları da dahil edilmelidir. Bunun ilave edilmesi durumunda, bireyler, ne zaman ve nerede ihtiyacı olduğu noktasında, kendi iradelerinde kendilerine münhasır ulaştırma türlerine (bisiklet, elektrikli bisiklet, elektrikli otomobil) sahip olmaktadır. Sahip olmadan kullanmak ilkesini takip eden bu paylaşım sistemi, özel araçlar tarafından işgal edilen kamusal alan miktarının büyük ölçüde azaltılmasına yardımcı olmaktadır. Optimum değişenleri dikkate alan, bir özel, mobil ve elektronik hareketlilik desteği, günlük bütün elverişli araçların verimli bir şekilde kullanımına imkân tanımaktadır [1].

Hareketlilik arzı ile ilgili değişimler, kentin konumsal yapısı üzerinde de bir dönüşüme neden olmaktadır. Ulaştırma hizmetlerinin verimliliğini artırmak için, hareket merkezlerinin diğer bir deyişle 'hub'ların oluşturulmasını gerektirmektedir. Kentler de bu hareketlilik merkezleri civarında şekillenecektir. Paylaşımlı araç kullanımı sayesinde, kentsel alanlarda otopark yerleri için arazi tüketimi ise net bir şekilde azalacaktır. Bunun nedeni ise kentsel alanlardaki araçların günlük kullanım sürelerinin artması olarak gösterilebilir [2].

\section{OTONOM ARACLARDA GELISSIM SÜRECI}

Bir otonom aracın (OA) yapılandırılması için ilk bilinen kayda değer girişim 1977 yılında gerçekleştirilmiştir. Proje araştırması Japonya'daki Tsukuba Mekanik Mühendisliği Laboratuvarı tarafından icra edilmiştir. Araç cadde üzeri beyaz işaretlemelerin takip edilmesi sureti ile işlevlendirilmiş olup münhasır bir deneme şeridinde yaklaşık olaraktan $32,2 \mathrm{~km} / \mathrm{saat}$ hıza ulaşmıştır. Otonom araçların (OA) gelişimindeki atılım ise 1980'li yıllarda Münih Bundeswehr Üniversitesi'nde Ernst Dickmanns ve ekibinin çalışmaları ile gerçekleşmiştir. Bunların prototipi trafik olmaksızın karayolu üzerinde yaklaşık olarak $97 \mathrm{~km} / \mathrm{saat}$ hız yapmaya elverişli görünmektedir. Otonom araçların (OA) tarihindeki diğer bir önemli kilometre taşı ise AHS'nin 1997 yılında 20'den fazla tam otomat aracı içeren devrim niteliğindeki sunumudur [3]. Bu sunum Kaliforniya otoyolunda yapılmış ve herhangi bir arıza olmadan tamamlanmıştır. Söz konusu bu etkinlik 2005 yılı DARPA Mücadelesine kadar Amerika Birleşik Devletleri'ndeki (ABD) herhangi bir akıllı ulaştırma sistemleri (AUS) etkinliğinin en yoğun ilgisine mazhar olanı durumundadır. Günümüzde Kasım 2007'de kentsel çevrede yer alan DARPA kentsel zorluğu da bir başka önemli girişim olarak kayıtlara geçmiştir.

1990'lar boyunca araç otomasyon sistemleri için temel yetkinlik sırası ile PROMETHEUS Programı, AHSRA (İleri Seyir Destekli Otoyol Sistemi Araştırma Birliği) ve AHS (Otomat Otoyol Sistemi) programları tarafından Avrupa, Japonya ve Amerika Birleşik Devletleri'nde (ABD) gösterilmiştir. Amerika Birleşik Devletleri (ABD) projeleri ise bu söz konusu otonom araç (OA) sistemlerinden her ikisini de kullanmaktadırlar [4]. 1990'ların projeleri ise muazzam ve eşsizdir. Amerika Birleşik Devletleri'nin (ABD) ASH programı zorlu Demo'97 ile sonuçlanmıştır. Proje, zaman kurgusunda çok uzun olduğundan dolayı söz konusu gösterimden sonra devre dışı bırakılmıştır. Bu bağlamda 2000'den fazla küçük ve özel teşebbüs ortaya çıkmıştır. Hâlihazırda çok ayıda küçük ve orta ölçekli proje boyutlarından ötürü PROMETHEUS gibi programlarla eşleşmemektedir ve fakat otonom ulaştırmasının gelecek gelişimi için büyük bir potansiyele işaret etmektedir [5].

Tam uyarlanabilir seyir kontrolü (USK) ise otonom hız kontrolü kademeleri ile indirgenmiş uyarlanabilir seyir kontrolünün (USK) bir terkibidir. Sistem etkinleştirilebilir ve de kentsel sürüş ya da yüksek hız otoyol sürüşü ile indirgenmiş hız trafiği arasında uyarlanabilir. Bu da sürücüye, dönüşlere 
ve de çevrede ne olduğuna daha iyi konsantre olma imkânını tanımaktadır. Bu gelişim tam otonom bir aracı temin edilmesinde gereklidir ve hâlihazırda da ARCOS projesi dâhilinde de test aşamasındadır. Kaza öncesi gren desteği ise sürücünün gelmekte olan bir nesneye yakınlaşması dâhilindeki hızını hesaplamak sureti ile muhtemel çarpışmaları saptamak adına uyarlanabilir seyir kontrolünü (USK_ACC) kullanmaktadır. Eğer ki oran yeterince yüksekse sistem önceden frenleme yapar ve böylelikle de optimum frenleme başarılır. Bu da durma mesafesini azaltmaya yardımcı olmakta ve de eğer ki ortaya çıkar ise etkinin hızının indirgenmesini desteklemektedir.

Tam otonom bir yolcu aracının temin edilmesi adına hem yanal ve hem de boyuna kontrol sistemlerinin entegrasyonunun hatasız olması gerekmektedir. Bunlar kamunun sistemin güvenilirlik ve sağlamlığına inanabileceği noktasından hareketle geliştirilmelidirler. En erken dönem tam otonom sistemler ise indirgenmiş hız versiyonlu olarak üretilmişlerdir. $\mathrm{Bu}$ indirgenmiş hızlı uyarlanabilir seyir kontrolü (USK_ACC) ile şerit disiplini desteğinin bir terkibi olabilir. Bu da yüksek trafik tıkanıklığa sahip yollarda kullanım için verimli görünmektedir. Bir akıllı otoyol sistemi (IHS_AOS) hâlihazırda Çin'de gelişim sürecindedir $\mathrm{Bu}$ da güvenlik alarmı ve trafik detayı gibi karayolu üzeri durum hakkında araca bilgi temin etmektedir. Akı1lı otoyol sistemi (IHS_AOS) aynı zamanda araçların otomat işletimini de desteklemektedir [6].

Amerika Birleşik Devletleri (ABD) Emek Departmanı, 2004 yılında Boston metropoliten alanında bir mesleki istihdam istatistik araştırması gerçekleştirmiştir. Bu söz konusu araştırmaya göre ağır tır sürücüsü olarak 12.930 kişi istihdam edilmektedir ve her birisi ortalama 41.120 ABD Dolar1/yıl maaş almaktadır. Sürücülere bu alanda artık daha fazla ihtiyacın olmaması ile birlikte tır şirketleri sürücü istihdamı için harcadığı toplamda 531.681.600 ABD Doları meblağı tasarruf edecektir ya da bunu iş araştırma ve geliştirmede harcayacaktır. Sadece yük nakliye şirketleri etkilenmeyecektir ve fakat aynı zamanda da UPS ve FedEX gibi kargo şirketleri de otonom araçlardan (OA) faydalanma yolunu seçebilecektir. Bir kamyon insanlara kargolarını ulaştırmak üzere kapıdan kapıya otonom sürüş gerçekleştirebilir. Söz konusu mesleki istihdam araştırması 10.240 işçi tespit etmiş olup bunların maaşları ise $31.540 \mathrm{ABD}$ Doları/yıl değerindedir. Ayrıca bundan feragat edilmesi ile de yıllık ilave bir 322.969.600 ABD Doları tasarruf temin edilecektir ancak bu da binlerce insanın işsiz kalması anlamına da gelmektedir. Eğer bu gerçekleştirilecek ise bir denge noktası sağlanması gerekmektedir. Aynı sektörün farklı kollarında söz konusu insanların aktarılıp ikame edileceği yeni alanlar oluşturulması gerekli görünmektedir [7].

Daha ileri araç paylaşım sistemleri ve toplu ulaştırmadaki değişim otonom araçların (OA) kullanımı vasıtası ile esasen mümkün görünmektedir ve birçok yerde aynı zamanda karayolu kullanıcıları için açık tanımlı faydaları teşkil etmektedir. Araç paylaşımında tam otomat indi bindi hizmetleri, vale otopark sistemi mantığı ile eğer ki araç paylaşım elverişliliği ve kullanımı orta vadede daha da fazla gelişir ise hemen hemen mantıklı ve gerekli bir sonuca dönüşecek gibi görünmektedir.

Mevcut durumda araç ve sürüş paylaşımı ile ilgili çok sayıda yeni fikrin test edildiği ve ortaya çıktığ1 görülmekte olup hatta bunlar otonom araçlar (OA) ile terkip edildiğinde daha büyük bir kapasiteye de ulaşabilecektir. Araç havuzlama planı geliştirilmiş olup örneğin sadece yaşlılar için değil aynı zamanda çocuklar için de ek bir dikkat aşaması Mercedes Benz desteği adı altında Kaliforniya'da Palo Alto'da gösterilmektedir. Aynı zamanda burada bu gibi hizmetler organize edildiğinde hareketlilik ve bilgi ve iletişim teknolojileri arasından sıkı bir bağlantı görülmektedir [8].

Otomotiv sanayi ise hâlihazırda otonom araçlar (OA) boyunca bir karayolu üzerinde olup SAE standartlarına göre ise düzey 4 ve düzey 5 otomasyonlarını ifade eden insan denetimi ya da müdahalesi olmaksızın kendi manevralarını gerçekleştirebilmektedir. Bu araçlar gerçek zamanlı bir trafikte diğer araçlarla birlikte hem manüel ve hem de otomatik olarak yayalar, bisikletliler ve diğer bütün çeşit karayolu kullanıcıları ile birlikte işletilmektedir. Dolayısı ile bu davranış yüksek önemde olmaktadır.

Düzey 4 otomasyonunu ve ötesini karayollarında uygulamak adına otomotiv sanayinin işlevsel güvenliğini sağlamak için ISO26262 standardında önerilen sürecin takibi gerekmektedir. Bunun pratikteki anlamı ise de net güvenlik gereksinimleri için bozulma olasılığının $10^{-9}$ 'dan küçük olmasıdır. Karar alma modülündeki bu gibi gereksinimlerin bozulması dâhilinde 1'den fazla olmayan yanlış karar 
$10^{9}$ işletim saati içerisinde gerçekleştirilmelidir. Bu gibi bir entegrasyon ve düzeltme düzeyinin başarılması, herhangi bir yaklaşımı münhasıran simülasyona, saha testlerine, istatistiksel veri yetersizliği ve gerçek dışılığa dayalı kılmaktadır. 2016 yılında Kalra ve Paddock'un yaptığı bir çalışmada vurgulandığ 1 üzere eğer ki 100 otonom araçlık (OA) bir filo ortalama $25 \mathrm{mil} / \mathrm{saat}$ 'lik (40 $\mathrm{km} / \mathrm{saat}$ ) bir hızla yılın bütün günleri 24'er saat sürülüyor ise 100 milyon mil başına 1,09 ölümlük insan sürüş hatasından daha iyi bir şekilde \%20'lik bir kayıp oranına sahip olmaktadır [9].

Otonom araçlar (OA) ulaştırma sistemlerinin güvenliğinin sağlanmasında önemli bir rol oynamaktadır. Bunun ile de beraber otonom araçlar (OA) kendi iç güvenlik ve emniyet zorlukları ile de karşı karşıya olmaktadır (9). Eğer ki otonom araçların (OA) bir unsuru bozulur ya da saldırıya uğrar ise araç içi ağ bu durumdan etkilenmektedir, ardından da araç üzeri bilgisayar yanlış komut alabilir ve de trafik güvenliğini doğrudan sekteye uğratabilir. Örneğin bozulmuş ya da kurcalanmış küresel konumlanma sistemi (KKS_GPS) verisi, otonom araçların (OA) konumlanmasını etkilemektedir ve trafik düzensizliklerine ve çarpışma risklerine yol açmaktadır. Dahası yanlış bilgi, mücavir alandaki otonom araçlara $(\mathrm{OA})$ da ulaştırılacak olup bu da tehlikeli bir duruma işaret etmektedir. Dolayısı ile de güvenlik ve emniyet, otonom araçlar (OA) için hayati olmaktadır. Yeterli güvenlik ve emniyet önlemleri, saldırılar ve bozulmaları azaltmak ve/ya önlemek adına uygulana gelmektedir [10].

\section{OTONOM ARACLARDA GÜVENLIK VE EMNIYET}

Otonom araç (OA) güvenlik ve emniyeti oldukça geniş ve tartışmaya açık bir konudur. Dolayısı ile kabul edilmelidir ki, bu tarz çalışmalar kapsamında otonom araçların (OA) bütün güvenlik ve emniyet aşamaları en detaylı ve kapsamlı bir şekilde test edilmelidir. Akıllı ulaştırma sistemleri (AUS_ITS) ile kriptolu çözümler mevcut olmasına karşın, otonom araçlar (OA) üzerinde muhtelif siber saldırılar olabilir. Siber güvenliğin zayıf noktaları ve güçlendirme çalışmaları bağlamında otonom araçlarla (OA) ilgili bir inceleme temin etmesinin yanı sıra da aynı zamanda bağlantılı ve otonom araç (BOA) sektöründeki siber güvenlik zorluklarına ilişkin sorulara da cevap verebilmektedir [11].

Ortaya konulan çalışmalar temelde emniyet konularına odaklanmaktadır. Bunun ile de beraber otonom araçlarda (OA) güvenlik ve emniyet birbirleri ile bağlantılı olup bunun nedeni ise de hem bozulmaların ve hem de saldırıların güvenlik kayıplarına yol açmasıdır. Dolayısı ile diğer çalışmalara nazaran otonom araçların (OA) zorlukları ve son durumun daha kapsamlı bir incelemesinin temini adına; güvenlik bozulmaları, emniyete yönelik saldırılar ve mütekabil önlemler değerlendirilmektedir. Otonom araçlar (OA) ağ imkânına sahip olduğundan dolayı da otonom araçlardaki (OA) bozulmalar ve saldırılar aynı zamanda, ăg üzerindeki diğer bağlantılı olanları otonom araçları da etkilemektedir. Araçtan altyapıya iletişim (V2I_AAL) ve araçtan araca iletişim (V2I_AA) vasıtası ile altyapı ve araç boyunca teşekkül eden ağ, araca mahsus ağlar (VANET_ARMĀR) olarak bilinmektedir. Araca mahsus ağlar (VANET_ARMAR) bağlantılı araçlar ve altyapı boyunca bilginin aktarılması imkânını da tanımaktadır. Araca mah̆hus ağlar (VANET ARMAR) akıllı ulaştırma sistemi (UAS) kurgusundaki anahtar kısımdır. Akıllı ulaştırma sistemleri (AŪS) ulaştırma sisteminin gelişmiş güvenlik, verimlilik ve hareketliliği için trafik yönetimini optimize etmek adına bilgi paylaşımını entegre edecek ve analiz edecektir. Örneğin akıllı ulaştırma sistemleri (AUS) araçları trafik tıkanıklığı olan alanlara sevk etmektedir ve dinamik olarak zirve saatler ve zirve dışı saatlerde karayolu hız sınırlarını ayarlamaktadır [12]. Amerika Birleșik Devletleri (ABD) otoyol güvenliği el kılavuzu vurgulamaktadır ki altyapı üzerinde uygulanan uygun önlemler karayolu kazalarını etkin bir şekilde azaltabilir. Örneğin yaya bariyeri ve yüksek görünürlüğe sahip yaya geçitleri ise karayolları boyunca yaya yolları da dâhil olmak üzere trafik kazalarını \%71 azaltmaktadır. Sola dönüş cepleri ve aşamaları, Missouri’de ölümlü ve yaralanmalı kazaları \%54 azaltmaktadır ve de kavşaklarla bağlantılı kaza yaralanma oranlarını da \%30 düzeylerinde azaltmaktadır. Kısmi aşama zamanlaması ve artan yaya geçişi süresi kavşaklarda yaya araç çarpışmalarında \%60'a varan azalmaları beraberinde getirmektedir [13].

Modern araçlar, mühendislerin bazen hayat üçgeni olarak tabir ettiği boşluğu da içermektedir. Yaşam üçgenleri daha muhtemel olan minimal kazalar dâhilinde bir kazadan kaçınma ihtimaliyeti dâhilindeki 
araç kullanıcıları çevresindeki korumalı alandır. Kaza değerleme sistemi/gereci bir pasif önlem çeşididir. Çökme bölgesi, emniyet kemeri, hava yastığı, kafalık ve ön cam levhası kaza değerleme sistemleri/gereçlerinin genel örneklerini teşkil etmektedir. Çökme bölgeleri, kaza kuvvetleri sürücü ve yolcu koltuğuna ulaşmadan önce kaza kuvvetlerinin emilimi ve dağıtılmasına yardımcı olmaktadır. Benzer şekilde emniyet kemerleri, hava yastıkları ve kafalıklar, sürücü ve yolcunun hareketsiz bir şekilde araçtaki yaşam boşluğunda durmalarına yardımcı olmaktadır [14].

\section{A. OTONOM ARAÇ TEKNOLOJILERI}

Son 50 yıldır mühendisler araç sürüşlerinde insan girdisini minimize etmek adına anahtar çözüme ulaşmak için daha ileri araştırmalara yönelmişlerdir. Jansson'ın çalışmasına göre araç kazalarının \%93'ü insan hatalarından kaynaklanmaktadır ve Lübnan Kızılhaç’ı ortaya çıkarmıştır ki 2014 yılında araç kazaları 14.516 can kaybına neden olmuştur. Bu şok edici istatistikler Zlocki ve arkadaşlarının çalışmasında ifade ettiği gibi yavaş gelişen hâlihazırdaki altyapı üzerindeki istikrarlı artan trafik yoğunluğuna bağlı olmaktadır. İnsansız araçları geliştirmek adına gereksinim; söz konusu bu hataların saf dışı edilmesi ve daha da önemlisi insan hayatına kıyılmaması adına ortaya çıkmaktadır [15].

$\mathrm{Bu}$ söz konusu teknolojinin avantaj ve dezavantajlarını inceledikten sonra araştırmacılar, yeni bir teknolojinin getirmiş olduğu herhangi bir ekonomik probleme benzer olarak ortaya çıabilen ekonomik kaygılar bağlamında faydaların dezavantajlara ağır bastığı sonucunu gerçeklemiştir. Bu konu bir hayli zamandır söz konusudur ve insanlar yeni teknolojiler ile başa çıkmak için diğer sahalardaki deneyimlerden de faydalanmaktadır. Bu noktada hâlihazırda otonom araçlara (OA) karayollarında niye rastlanılmadığı hususu önemli olmaktadır. Birçok senaryoda söz konusu araçlar gerçek zamanlı dünya ve koşullarla yüzleşmektedir ve mevcut koşullarda bu araçların işletimi ile ilgili hâlihazırda üreticilerin pazara girişlerinden çekinmelerinin anlaşılır sebepleri vardır.

Bu kapsamda araçlarda çoklu otomasyon sistemi çalışmaları yapılmaktadır. Bu sistemlerden bir tanesi izleme sistemi olup aracın yerleşimini ortaya koymaktadır. Quddus ve Noland tarafından geliştirilen bir sistem dijital yol haritalarını kullanmakta olup, 1şı görüntüsü saptama ve kademelendirme (LIDAR_IGSVK) sensörünü kullanmak sureti ile kurbu ve karayolu sinırlarını saptayan karayolu görüntüsü elde edilmekte ve mevcut yol haritaları ile karşılaştırılmaktadır. Bu bağlamda Kojima ve arkadaşları tarafından yapılan bir çalışmada ise bir izleme sistem araç yerleşimini net bir şekilde hesaplamak için küresel konumlanma sistemi (KKS_GPS) konum verisini kullanmaktadır. Bu bağlamda koordinatlara göre araç yerleşimini net bir şekilde belirlemek adına araç mücavir alanını izlemek için bir lazer tarayıcıdan faydalanmaktadır ve dolayısı ile de mücavir alandaki nesnelerin görece konum değişimi sureti ile bu durumu geliştirmektedir. Buna ilave olaraktan işaret izleme sistemleri, Zhu ve Chen'in çalışmasına göre belirli işaretler ya da hatları birleştirmek sureti ile de aracı konumlandırmaktadır. Diğer otomasyon sistemleri ise çarpışma önleme sistemlerini içermektedir. Muhtemel bir çarpışma ile karşılaşıldığında ise bir sürücü iki seçeneğe sahip olup bunlar ya frenlemek ya da doğrultu değiştirmektir. Labayrade ve arkadaşlarının çalışması bir engel ile karşılaşmadan önce ya da diğer araçlarla güvenli takip mesafesini korurken aracın frenlemesi ya da durmasının kontrolü için bir boyuna çarpışma önleme sistemini uygulamaktadır [16].

Başlangıç otonom araç (OA) modelleme çabaları ise de otonom araç (OA) teknolojisi 1şığında araç düzeyli etkileşimin tanımlamasının incelenmesi dâhilinde ağırlıklı olaraktan mikroskobik bir perspektifte hesaplanmaktadır. 2010 yılında Kestim ve arkadaşları ise uyarlamalı seyir kontrolünün (USK_ACC) etkilerinin modellenmesi adına uyarlamalı bir akıllı sürüş modeli (ASM_IDM) araç takibini kullanmakta olup bu da otomat bir sürüş stratejisini teşkil etmektedir. Benzer bir şekilde 2016 yılında Li ve arkadaşları ise birbirine yakın seyreden araçların gaz pedalını kullanma bilgisinin paylaşılmasına ve de araçtan araca (AA_V2V) iletişiminin de entegre edilmesi sureti ile de tam hız farkına (FVD_THF) dayalı olaraktan bir araç takip modelini önermektedir. Alternatif bir yaklaşım ise hâlihazırdaki araç takip modellerini kullanmaktadır; fakat insan sürücülü standart araçtan farklı olaraktan davranabilen otonom araçların (OA) davranışlarını ihtiva edebilmek adına unsur değerlerini değiştirip geliştirmektedir. Araç intikal süresinin daha düşük değerleri, otonom araçlar (OA) için ayırt edici bir özellik olduğundan dolayı da bu alandaki otonom olmayan diğer araçlar reaksiyon süresinin etkisi ya da trafik davranışı ile ilgili gecikme etkisi ile ilgili görüşleri temin etmektedir [17]. 
Algı sistemi tasarımı bir otonom aracın (OA) gelişiminde hayati bir adımı teşkil etmektedir. Ticari araçlar ve araştırmada uygulanan sensör sistemlerinin uygun üretime hazır taslakları ve görünen sonsuz seçeneklerinin büyüklüğü dahilinde bir otonom araç (OA) uygulaması için optimum sistemin tayin edilmesi adına bu durum zor olabilmektedir. Bu kapsamdaki çalışmalarda ise, son model otonom araç (OA) günümüz algı teknolojisinin kapsamlı bir incelemesi sunulmaktadır. Günümüze kadar; otonom araç (OA) araştırmasında uygulanan hâlihazırdaki yöntemlerin haritalandırılması ve yerleşimi ile pazardaki hâlihazırdaki otonom özellikleri, ticari otonom araçlar (OA), hâlihazırdaki araştırmalardaki en yaygın sensörler, belirli otonom araç (OA) sensörlerinin ideal uygulamaları ile avantajlar, dezavantajlar ve sınırlar hakkında güncel bilgi de temin etmektedir [18].

Bu çerçevede şunun not edilmesi de önemlidir, konumlanma ve haritalanma bölümü münhasır mücavir alanda tam otonom aracın (OA) nasıl bir algı kapsamı temin ettiğini ortaya koymaktadır. Örnek olarak eğer bir otonom araç (OA) bir yaya geçidinin yakınında ise araç, algılamadaki önceliği yaya geçidi alanındaki yayaya vermelidir. Algılama ve sensör, konumlanma ve haritalama işleri arasındaki ilişki ters yönlü olmaktadır. Bu bağlamda örneğin eğer ki bir araç solunda ya da sağındaki karayolu işaretlerini sensör ile tespit ediyor ise karayolu ağının merkezindedir, dolayısı ile de konumlanma algoritmaları da birbirlerine bağlantılı olarak güncellenmek durumundadır [19].

20.yüzyılın son çeyreğinden beri araştırma ve üretim paydaşları gerçek sürüşlerde yüksek hızlı bir ulaştırma sistemi dâhilinde güvenli, güvenilir ve dayanıklı olacak bir şekilde tam otonom bir aracın üretimi adına hummalı çalışmalar yürütmektedir. Erken dönem otonom araç (OA) araştırmalarının ana katılımcıları ise dünya genelindeki otonom araç $(\mathrm{OA})$ test ve rekabetinin merkezindedir. İfade edilen rekabet muhtelif sürüş mücavir alanlarında otonom araçların yeterliliği ve limitlerinin ele alınması için önemli imkânları ilgili paydaşlara sunmaktadır. Bu çerçevede üzerinde çalışmalar devam eden otonom araçların yazılım ve donanım ile ilgili hususları hakkında aydınlatıcı olmaktadır.

Araçtan altyapıya (AAL_V2I) ve araçtan araca (AA_V2V) iletişim gibi bağlantılı araç teknolojileri öncül bir bilgideki yüksek güvenilirlik kaynaklı hâlihazırdaki problemlerin bir bölümünü çözümüne yetkin ve yeterli görünmektedir. Araçtan altyapıya (AAL_V2I) iletişim; otonom araçlar ile her türlü yol ve trafik altyapısı, sinyalizasyonu arası iletişim ve veri akışını ifade etmektedir. Öte yandan araçtan araca (AA_V2V) iletişim, aracın şerit değişimi, sollama, hız azaltma ya da arttırma durumları için diğer araçlarla iletişime geçerek veri aktarımı ve alımını gerçekleştirmesi durumudur. Otonom araç (OA) teknolojisi dâhilinde araçtan araca (AA_V2V) iletişim ve araçtan altyapıya (AAL_V2I) iletişimin entegre edilmesi sureti ile de etkin bir ortak sürüş ağı kurulabilmektedir [20].

Genelde ise otonom araç (OA) geliştiricileri; araçların mücavir alanlarının saptanması adına 1şık, ses ve/ya görsel tabanlı sensörlerin farklı terkiplerini kullanmaktadırlar. Söz konusu bu sensörler ise LIDAR gibi aktif sensörlerden daha az maliyetli olan hâlihazırdaki pasif sensörlerin çoğu ile hem aktif ve hem de pasif olabilmektedir. Bunun ile de beraber aktif sensör fiyatları; Velodyne gibi LIDAR'a büyük yatırım yapan şirketler ve düşük maliyetli geliştirme yapmayı hedefleyen Innoviz gibi başlangıç şirketlerinin gelişmesi dâhilinde dramatik ölçülerde düşüşler gösterebilir. Buna ilave olaraktan; bu çerçevede otonom araç (OA) teknolojisinin gelişimi aktif sensör artışını kullandığından dolayı da bu sensörleri pratik olmaktan çıkaracak bir şekilde aktif sinyaller birbirilerine engel olmaya da başlayabilir. Örneğin yüksek yoğunluklu trafik koşullarında ise radar sistemleri diğer araçlardan radar sinyallerini alabilmekte, bu da sinyal karışmalarına, hatalı saptamalara ve ilave belirsizliklere neden olmaktadır. Görsel tabanlı sistemler bu söz konusu zorlukla karșlaşmamakta olup gelecek dönemlerdeki otonom araç $(\mathrm{OA})$ sistemleri için öncül bir algı türü olduğundan dolayı görüntüye odaklanmak adına çeşitli araştırmacıları yönlendiren bir anahtar unsur olmaktadır [21].

\section{IV.SONUC}


Otonom araçların (OA) yaygınlaşması, araçların verimliliğini ve ayrıca ulaşım ağı kullanım verimliliğini artıracaktır. Bunun yanında, trafik güvenliğine de önemli oranda katkı sağlayacaktır. Ancak, otonom araçlar (OA) halen hâlihazırda emniyet ve güvenlik sorunları ile birlikte hukuksal altyapı ile ilgili çözülmemiş bir dizi problemlere sahiptir. Özelikle siber saldırılar ve Vandalizm gibi önemli problemler henüz çözüme tam olarak ulaştırılabilmiş değildir. Bu bağlamda, tam otonom (seviye 5) araçların trafiğe çıkması ve kabul görmesi uzun yıllar alabilir [22].

$\mathrm{Bu}$ çerçevede otonom araçların (OA) trafiğe tam olarak penetre etmesi sürecinde belki 50 ylllık bir karma trafik ara döneminden söz etmek mümkün görünmektedir. $\mathrm{Bu}$ dönemde trafiğin karma olmasından kasıt otonom araçlar (OA) ve mevcut otomobillerden oluşması olduğu gibi bunun yanı sıra otonom araçların (OA) muhtelif seviyelerinin de trafikte beraber olmasını da içermektedir [23]. Dolayısı ile belki yarım yüzyıllık bir süreçte karma trafik içerisinde otonom araçların (OA) kademeli olarak trafik kesimlerine ve küresel ulaştırma sisteminin bütününe penetre ettiği bir durum ortaya çıkacaktır. Dolayısı ile de bu durumun iyi bir şekilde planlanması ve düzenlenmesi çok önemlidir. Ekonomik, teknik, sosyal ve politik yönleri itibari ile bu önem söz konusu olmakta olup bu geçiş sürecinin senaryolarının simülasyon yolu ile ortaya konulması ve farklılaşan otonom araç (OA) yoğunluklarına göre çözümlerin geliştirilmesi ile en sonunda otonom araçlardan (OA) homojen bir şekilde oluşan bir trafiğe sağlıklı bir yolla ulaşılması mümkün olacaktır [24]. En nihayetinde otonom araçların (OA) tam penetrasyonu ve tam otonominin ulaştırma sisteminde temini ile birlikte derinlemesine olarak yeniden şekillenmiş bir ulaştırma ve kentleşme ortaya çıkmış olacaktır.

TEȘEKKÜR: Bu çalışmada bize destek olan değerli hoca ve meslektaşlarımıza teşekkür ederiz.

\section{KAYNAKLAR}

[1] K. Lindemann, "BCS (Bundesverband CarSharing): Datenblatt CarSharing in Deutschland", Hochschule, vol. 5, pp. 3, 2014.

[2] K. Breindl, "CarSharing ist auch in kleinen Städten möglich. In: Bundesverband CarSharing e.V. (eds.): Eine Idee setzt sich durCh. 25 Jahre CarSharing. Brühl (kölner stadt- und verkehrsverlag) ", Mobility Tech Green, vol. 4, pp. 67-76, 2014.

[3] J. Anderson, "Autonomous Vehicle Technology", RAND, vol.3, pp. 8. 2007

[4] J. Schmidhuber, "Highlights of Robot Car History", WPI, vol. 3, pp. 40-44. 2005

[5] A. Davila, E. Aramburu and A. Freixas, "Making the best out of aerodynamics: Platoons. In: SAE Technical Paper. ", SAE International, vol. 3, pp. 1-6. Apr 2013.

[6] J. Golson "Tesla's autopilot system is reportedly getting more sensors. Google self-driving car project", IEEE, vol.7, pp. 315-329. 2017.

[7] S. Guler, M. Menendez and L. Meier, "Using connected vehicle technology to improve the efficiency of intersections". Transp. Res., vol. 3, pp. 121-131, 2017.

[8] Öko-Institut; Institut für sozialökologische Forschung "SHARE - Forschung zum neuen Carsharing. Wissenschaftliche Begleitforschung zu Car2Go", Halbzeit, vol. 3, pp. 1-3, 2014.

[9] Z. Fei, S. Miremadi, K. Akesson and B. Lennartson, "Efficient symbolic supervisor synthesis for extended finite automata," IEEE Transactions on Control Systems Technology, vol. 4, pp. 23682375, 2014.

[10] N. Kalra and M. Paddock. "Driving to Safety: How Many Miles of Driving Would It Take to Demonstrate Autonomous Vehicle Reliability? ", RAND, vol. 4, pp.8, 2016. 
[11] J. Cui and G. Sabaliauskaite "On the alignment of safety and security for autonomous vehicles", IARIA, vol. 4, pp. 59-64. 2017.

[12] H. Hasrouny, E. Samhat, C. Bassil and A. Laouiti, "Vanet security challenges and solutions: a survey, Veh. Commun". IEEE Intell. Transp. Syst., vol. 18, no.3, pp. 516-526, 2017.

[13] A. Vaibhav, D. Shukla, S. Das, S. Sahana and P. Johri, "Security challenges, authentication, application and trust models for vehicular Ad Hoc network-a survey," MDPI, vol. 5, pp. 9131-9138, 2017

[14] Society of Automotive Engineers (SAE), "SAE-J3016: Taxonomy and definitions for terms related to driving automation systems for on-Road motor vehicles“ $S A E$, vol. 28, pp. 4, 2016.

[15] P. Bhavsar, P. Das, M. Paugh, K. Dey and M. Chowdhury, "Risk analysis of autonomous vehicles in mixed traffic streams," Transportation Research Record, vol. 2625, no.1, pp. 51-61,2017

[16] M. Zhu, H. Chen and G. Xiong "A model predictive speed tracking control approach for autonomous ground vehicles”, Mechanical Systems and Signal Processing, vol. 4, pp. 138-152, 2017.

[17] J. Donga, S. Chenb, Y. Lia, R. Dua, A. Steinfeldc and S. Labia, "Facilitating connected autonomous vehicle operations using space-weighted information fusion and deep reinforcement learning based control" $S A E$, vol. 28, pp. 23-25, 2020

[18] D. Hess, "Incumbent-led transitions and civil society: Autonomous vehicle policy and consumer organizations in the United States", Technological Forecasting and Social Change, vol. 151, pp. 8. 2020

[19] I. Ashraf, S. Hur and Y. Park, "An Investigation of Interpolation Techniques to Generate 2D Intensity Image From LIDAR Data”, IEEE, vol. 99, pp. 1, 2017.

[20] T. Litman, "Autonomous Vehicle Implementation Predictions Implications for Transport Planning“, Victoria Transport Policy Institute, vol. 1, pp. 1-46, 2021

[21] Z. Cui, S. Yang and H. Tsai, "A vision-based hierarchical framework for autonomous frontvehicle taillights detection and signal recognition,", IEEE, vol. 7, pp. 931-937, 2015.

[22] M. Daraei, A. Vu and R. Manduchi, "Velocity and Shape from Tightly-Coupled LiDAR and Camera," IEEE, vol. 4, pp. 60-67, 2017

[23] D. Silva, D. Földes and C. Csiszár, "Autonomous Vehicle Use and Urban Space Transformation: A Scenario Building and Analysing Method“, Transportation Research, vol. 4, pp. 1-22, 2021

[24] X. Lin, F. Wang, B. Yang and W. Zhang, "Autonomous Vehicle Localization with Prior Visual Point Cloud Map Constraints in GNSS-Challenged Environments", MDPI, vol. 21, pp. 3703, 2021 